\title{
RISK MANAGEMENT TOOLS AND FINANCIAL PERFORMANCE OF COMMERCIAL BANKS IN RWANDA: A CASE STUDY OF BANQUE POPULAIRE DU RWANDA PUBLIC LIMITED COMPANY
}

\author{
Aimablebahati ${ }^{1 *}$, Mercyline Kamande ${ }^{2}$ \\ *1,2Mount Kenya University \\ *1Email: aimablee.bahati@gmail.com,Email:mkamande@mku.ac.ke
}

*Corresponding Author: -

Email: aimablee.bahati@gmail.com

\begin{abstract}
: -
The study is about risks management tools on financial performance of commercial banks in Rwanda, the case study of BPR Plc. The general objective of this research was to assess the contribution of risks management tools on financial performance of commercial banks in Rwanda, taking a case study of BPR. Specific objectives included to ascertain risks management tools used by BPR in managing its asset; to analyze the financial performance of BPR in Rwanda since 2015 to 2018 and to find the link amid risks management tools and financial performance of commercial banks in Rwanda. The results of this research are useful for academic purpose as reference, to institutions, which will access the findings to address risk issues and improve their control measures against risk. The main theory applied in this research is Agency theory. This research adopted descriptive and correlation research designs and is both qualitative and quantitative research. Forty-two (42) is target population used; census was applied in this research as the sampling technique since the target population is small and data were analyzed using SPSS version 20 to generate frequency tables, charts, and regression analysis. The research revealed that at BPR Plc, use of risk management tools has a great positive relationship with the financial performance of BPR as it is being indicated by the respondents about standard and reports, position limit and rules, investment guideline and strategies whether help in financial performance in BPR, many respondents were in agreement with this statement as it is indicated by a high means and homogeneity in responses as the standard deviations obtained for all items of independent variables were less than one $(S D<1)$. for objective two, it was seen that BPR Plc financial performance increased considerably since 2015 to 2018 as results of risk management tools; for relationship, the results found that risk management tools greatly influence $B P R$ financial performance as justified by $P$-values which are positive and statistically significant respectively for position limit and rules $(p=0.003)$, standard and reports $(p=0.034)$, investment guideline and strategies $(p=0.023)$ which are less than the significance level $(P<0.05)$ from multiple regression analysis. The conclusion is that risk management tools greatly influence banks financial performance. So far, much is already done by the Bank to overcome and mitigate risk in all BPR operations but there is need to emphasize on new strategies to improve on standards, rules and regulation to enforce risk mitigation. In today's BPR daily business; technology is increasing, process and procedures are tightened, account manipulation are restricted. This has greatly reduced reputation and financial risk leading to increase in financial performance. The further studies should be carried out on implementation of risk management strategies and financial performance in banking industry.
\end{abstract}

Keywords: - Risk management tools, financial performance, Commercial banks, Banque Populaire du Rwanda

\section{(a) $(\$)$}




\section{INTRODUCTION}

The banking industry face risk incidence and this is due to different factors like; high competition and changes resulting from technology, political and economic changes. After 1994 Genocide, Government of Rwanda has tried to put all necessary and required infrastructure in economic sectors in order to facilitate smooth economic development, goal and vision were clearly identified for instance Vision 2020. Due to Government of Rwanda acceleration in economic activities, banking sector in Rwanda also profited to improve its service from one level to another (MINECOFIN, 2011). BNR regulation No 11/2011 was put in place to emphasize on internal control and audit standards to be implemented by the banks in order to improve risk mitigation and this was intended to empower banks in risk management. Since 2011, there is remarkable change in bank performance due to different strategies adopted by banks but there is still gap to be filed in risk management that affect directly or indirectly financial performance.

All banks operate in order to maximize profit and become successful in business, this can be achieved if different measures related to risk management are applied successful (Kaplan, Davenport \& Norton, 2004). Recently, Risk result from credit default payment, stiff competition, inappropriate products, and technology advancement and innovation issues. Within BPR, risks management and control is not yet' on high standard to minimize all risk because there are still more written off loans, technology and Innovation issues that hinder bank performance. According to national bank of Rwanda financial report of July 2017 - June 2018, provision for bad debts was 17.1 billion in June 2016, 19.7 billion (June 2017), 23 billion (June 2018) which affect profitability and this shows consistent increase of high risk in bank industry. The overall loan rejection rate increased from 16.6 percent in the first half of 2017 to 20.4 percent in the first half of 2018 and this was due to increase of risk identified by the banks that hindered giving out loans and commercial banks targeted to recover un paid loans, for instance in the first six months of 2018, Frw 402.7 billion new loans (total) was approved by the banks which is lower that total loans approved in 2017 (416.7 billion). According to 2018 BPR annual report, operation risk statistics shows that 13,913,640,000 Rwf as Non-performing loans (NPL), written off loans equivalent to 8,438,542, 000 Rwf while fraud cases totaling to $46,115,000$ Rwf. Due to these risks mentioned, financial performance of BPR is affected negatively and indicates that risk management tools are missing to facilitate monitoring and control hence researcher intends to find out if tools required are in place and to fill the gap.

In addition, changes in foreign exchange rate that might lead to fraud or money laundering, inadequate internal control system, insufficient skilled experts, changes in customer needs, lead to increase of banking risks that are difficult to be controlled. Fortunately, there is a team in the bank deals with solving all risk issues but also implement control measures. Risks management is a very critical to be addressed in order to allow banking industry in Rwanda to perform efficiently and maximize profit. This is the reason that pushes the investigator to evaluate the part of risks management tools on financial performance of commercial banks in Rwanda, taking BPR Plc as a case study.

\subsection{Objectives of the study}

\subsubsection{General objective}

The general objective of the study is to assess the contribution of risks management tools on financial performance of commercial banks in Rwanda.

\subsubsection{Specific objectives}

(i) To ascertain risks management tools used by BPR to achieve higher financial performance.

(ii) To analyze the financial performance of BPR in relation to risk management tools in Rwanda.

(iii) To establish the relationship between risks management tools and financial performance of commercial bank in Rwanda.

\section{Review of Literature}

The previous studies conducted in this field of risks management tools on financial performance of commercial banks such as in the United State of America (USA) by Van and Bratanovic (2009) indicated that in USA credits risks mostly occur and this interrupt performance of most financial institutions. The rises of risks were due to some default payments among clients whom credits were extended not only in USA, because risks resulting from credits provision also reached developing countries in which economy is not stable due to market competition and changes in technology. The similar study conducted by Van and Bratanovic (2009), in USA also determined different distinction between internal and external factors associated with risks and which result to credit default payments and weakness in the structure of management system. In addition, technology, increase, decease in demands, competition and religion, market structure, regulations and institution's environment conditions are the external factors of credits default payments.

The study conducted by Naceur and Omran (2008), on the regulations and concentration on appropriate control within banking sector help to determine institutions' profits especially in Middle and East North Africa (MENA) countries. The credit risks represent significant positive impact on banking net profit margin result into costs effectiveness and profitability. Bank must have consistency in checking and evaluation to prevail risk that might arise. Whereas, study conducted by Kane (2008) recently, banks have extended their branches faster in order to deliver services they render using high technology compared to the old traditional banking method. Unfortunately, the banks have doubled services on market but services and products might not meet required standards hence 
abusing laws and regulations abiding in certain area distort the image and minimize performance of the bank. Sometimes banks do not apply regulations of central banks willing or unwilling, this expose penalty to the banks due to non-compliance. Not only paying penalties affecting profitability of the bank, has this also given chance to money laundering and fraud. Negative effects of noncompliance and weak banking system enables hackers to access easily financial data and customer's details leading to manipulation as quick as possible. To resolves issues related to fraud, manipulation and compliance issues, some countries have taken action and implement process and procedure governing all banks plus regular supervision to verify level of customer data security and compliance level.

The previous study conducted by Drehmann and Goodhart (2000) has also indicated that security violation and disruption of Bank's system damage the image of the banks and reduce market size. Depending more on electronic delivery channels like Mobile banking and internet transaction process has reputational risk to the banks in case of poor performance or network issues disappoint customer's expectation. Reputation risk is very crucial to the success of banking sector depending on technological capacity of the bank to tighten the security measures and resources in place to facilitate customer access service simply and efficiently. Problems related to poor service on technological service offered by the banks are commonly pronounced in third world countries due inability to invest in infrastructure to empower effective online banking and facilitating smooth business.

The research conducted by Ndegwa (2014) found out that service related to electronic banking requires to focus on customer's data security as a priority in their day-to-day business transactions due to minimum security involves internet hackers, which becomes tricky to monitor and control risk associated. Further still, today's technology advancement is highly increasing and electronic banking should be in line with changes to incorporate security measures and skilled staff in order to manage risk and implement sustainable solution to assure customers stability and reliability to use electronic bank and other channels. Banks has to outline and emphasize on securing online banking and definitely will improve on output depending on number of customers impressed to use system.

\subsection{Research gap}

According to Belassi and Tukel (1996), risk management tools are used to empower and facilitate the implementation to accelerate financial performance and success but research didn't consider the size of the bank and capacity of management to manage risk associated. Risk management tools might be already set within financial institution but once the size of the bank is large and complex, it requires board or executive committee to have close risk monitoring and assessment to ensure effective implementation. Having risk management tools in place without proper management definitely results will be less than expectation.

The study conducted by Epure and Lafuente (2015) in Spain showed that insufficient of investment capital and managerial role result into risks within banking sector. In this research, authors do not put more emphasis on the role of motivation towards employees and appropriate working condition reflect risks management and can further result into low financial performance. Technology and appropriate decision-making not put forward but normally they are of great advantage in banking sector.

\section{Materials and Methods}

The researcher used both descriptive and correlation research designs to describe event, as they exist in the field of study and assessing the relationship between risk management tools and financial performance. Questionnaires and interviews were adopted in the of data collection process signifying the use of qualitative and quantitative approaches in the both research designs. The total number of population is 42 in the three selected departments whereby the 7 of them are from risk, 10 from finance and 25 from the operations department. Therefore, the researcher applied census as the sampling technique since targeted population is small and manageable with resource and time available for the researcher.

Qualitative data were analyzed thematically and content analysis to assess the role risk management tools on financial performance of commercial banks in Rwanda. Whereas, SPSS 20 was used to analyze the quantitative data. Expressive and inferential statistics such as association applied to investigate this data. Mean and standard deviations were generated to attach meaning to the study variables. The research was presented using tables which enabled the researcher to meaningfully describe the distribution of scores and measurements. The linear regression model for this study was $\mathrm{Y}=\mathrm{pO}+\mathrm{p} 1 \mathrm{X} 1+\mathrm{p} 2 \mathrm{X} 3+\mathrm{p} 3 \mathrm{X} 3+\epsilon$, Where: $\mathrm{Y}=$ Financial Performance, $\mathrm{X} 1=$ Position limit and rules, $\mathrm{X} 2=$ Standard and reports, $\mathrm{X} 3=$ Investment guideline and strategies $\mathrm{pO}=$ the constant and $\epsilon=$ error term. 


\section{Research Findings}

4.1. To ascertain risk management tools used by BPR to manage its asset

Table 4. 1: Standard and reports

\begin{tabular}{llll}
\hline Statements & N & Mean Std. D \\
\hline standard and reports are part of internal control systems for risk management in BPR & 42 & 4.43 & .590 \\
BPR has set quality assurance standards that are easily communicated to all departments & 42 & 4.10 & .759 \\
Each department within the bank has a set of standards that guide it in controlling risks & 42 & 4.10 & .617 \\
within department & 42 & 3.71 & .708 \\
The guiding standards within the bank adhere to international banking standards & 42 & 3.90 & .878 \\
The banking standards within BPR promote the banks reputation and image & 42 & 3.86 & .783 \\
The standards followed by BPR have enhanced its financial performance for last four years & 42 & 4.62 & .492 \\
BPR reporting standards comply with the regulator's (BNR) standards & 42 & 4.19 & .671 \\
BPR frequently reviews its standards to promote efficiency within the bank & 42 & 4.62 & .492 \\
Financial reporting within the bank are audited to reduce cases of audit risk & 42 & 4.14 & .566 \\
BPR maintains standards of professional conduct in its operations in all departments & 42 & 4.10 & .759 \\
There is ethical standards within the bank that helps in risk mitigation & 42 & 3.67 & 1.004 \\
Regularly upcoming risk are reported to staff accordingly to avoid future reoccurrence & $\mathbf{4 2}$ & $\mathbf{4 . 1 2}$ & $\mathbf{. 6 9 3}$ \\
\hline Average
\end{tabular}

Source: Primary Data, 2021

As portrayed in Table 4.1 there is agreement that standard and reports are part of internal control systems for risk management in BPR and is very important on the mean of 4.43 and expressed as very high mean and homogeneity in responses as the standard deviation is 0.590 which is less than one (SD $<1)$. It is seen also that feedback (respondents), many agreed on the statement that BPR has set quality assurance standards that are easily communicated to all departments by 4.10 as high mean and homogeneity in responses as the standard deviation is 0.759 which is less than one $(\mathrm{SD}<1)$. Respondents in table 4.1 also shows that many respondents concurred that each department within the bank has a set of standards that guide it in controlling risks within department as exposed high Mean as 4.10 and homogeneity in responses as the standard deviation is 0.617 which is less than one $(\mathrm{SD}<1)$.

The guiding standards within the bank adhere to international banking standards on a high mean of 3.71 and homogeneity in responses as the standard deviation of 0.708 is less than one (SD<1); the banking standards within BPR promote the banks reputation and image on a high mean of 3.90 and homogeneity in responses as the standard deviation of 0.878 is less than one $(\mathrm{SD}<1)$; the standards followed by BPR have enhanced its financial performance for last four years on a high mean of 3.86 and homogeneity in responses as the standard deviation of 0.783 is less than one ( $\mathrm{SD}<1)$; BPR reporting standards comply with the regulator's (BNR) standards which is 4.62 high mean and homogeneity in responses of 0.492 as the standard deviation which is less than one (SD<1); BPR frequently reviews its standards to promote efficiency within the bank on 4.19 as high mean and homogeneity in responses 0.671 as the standard deviation which is less than one (SD<1),financial reporting within the bank are audited to reduce cases of audit risk on a very high mean of 4.62and homogeneity in responses as the standard deviation of 0.492 is less than one $(\mathrm{SD}<1)$; BPR maintains standards of professional conduct in its operations in all departments of 4.14 a high mean and homogeneity in responses (0.566) since the standard deviation of is less than one $(\mathrm{SD}<1)$; there are ethical standards within the bank that helps in risk mitigation of 4.10 (as high mean) and homogeneity in responses as the standard deviation of 0.759 is less than one (SD<1) and finally, regularly upcoming risk are reported to staff accordingly to avoid future reoccurrence on a high mean of 3.67 and heterogeneity in responses as the standard deviation of 1.004 is greater than one(SD>1).

Table 4. 2: Position limit and Rules

\begin{tabular}{llcc}
\hline Statements & N & Mean Std. D \\
\hline $\begin{array}{l}\text { BPR has well defined position limit and rules that govern the institution and each of the } \\
\text { departments }\end{array}$ & 4.00 & .765 \\
The set position limits and rules govern the operations of the bank within and with partners. & 42 & 4.05 & .582 \\
Every individual within the bank is aware of his/her position and limits & 42 & 4.19 & .594 \\
Position limits within the bank help in providing timely identification, measurement, 42 & 3.81 & .740 \\
monitoring and control of its risk & 42 & 3.95 & .582 \\
The position limits for BPR are within the organizational set goals and objectives & 42 & 3.81 & .917 \\
Risk limits within the bank are effectively communicated to all parties & 42 & 3.95 & .731 \\
Internal position limits are adhered to within the bank & 42 & 4.33 & .570 \\
There are clear guidance on the signatories mandated by the management & 42 & 4.33 & .570 \\
The set protocol for signing documents and approving are clearly defined and adhered to. & $\mathbf{4 2} \mathbf{4 . 0 4 6} \mathbf{. 6 7 2}$ \\
Average
\end{tabular}


Table 4.2 results indicate BPR as well defined position limit and rules that govern the institution and each of the departments has 4.00 as high mean and 0.765 homogeneity standard deviation in responses; the set position limits and rules govern the operations of the bank within and with partners of 4.05 (high mean) and 0.582 of homogeneity standard deviation; on the statement namely, every individual within the bank is aware of his/her position and limits on a high mean of 4.19 and homogeneity standard deviation of 0.594; again respondents on position limits within the bank help in providing timely identification, measurement, monitoring and control of its risk of 3.81 (high mean) and a standard deviation of 0.740 . in addition, the table 4.2 indicated many respondents agreed on the position limits for BPR are within the organizational set goals and objectives on the high mean of 3.95 and 0.582 as standard deviation; about the risk limits within the bank are effectively communicated to all parties, almost all respondents agreed as indicated by 3.81 as high mean and homogeneity shown by 0.917 as standard deviation; about whether internal position limits are adhered to within the bank, many respondents concurred on high mean 3.95 and a standard deviation of 0.731 . Furthermore, the table 4.2 results revealed that there is clear guidance on the signatories mandated by the management on a high mean of

4.33 and 0.570 of standard deviation; finally, respondents were asked if the set protocol for signing documents and approving are clearly defined and adhered to at BPR and many of them were in agreement on a high mean which is 4.33 and a standard deviation of 0.570 .

Table 4. 3: Investment guideline and strategies in BPR

\begin{tabular}{|c|c|c|c|}
\hline Statements & $\mathrm{N}$ & Mean & Std. D \\
\hline Providing clear guidance, procedures and controls is crucial in risk management of a bank. & 42 & 4.24 & .759 \\
\hline BPR has guidance, procedures and controls as risk controlling tool. & 42 & 4.14 & .718 \\
\hline $\begin{array}{l}\text { Guidelines on the price risk in the bank's investment portfolio are clearly defined and } \\
\text { communicated }\end{array}$ & 42 & 3.67 & 1.004 \\
\hline There are sufficient rules on investment risks in relation to foreign exchange and trade. & 42 & 3.76 & .532 \\
\hline There are sufficient and effective guidelines involving interest risk & 42 & 3.76 & .759 \\
\hline The bank adhere to guidelines on investment concentration by diversify its investments & 42 & 3.62 & .795 \\
\hline All investment activities and decisions are deliberated and cross checked before approval & 42 & 3.62 & .909 \\
\hline Investment strategies are well defined in BPR to ensure progress & 42 & 3.62 & .909 \\
\hline Average & 42 & 3.803 & .793 \\
\hline
\end{tabular}

Source: Primary Data, 2021

The Table 4.3 it is clear that many respondents agreed on providing clear guidance, procedures and controls is crucial in risk management of a bank on a very high mean of 4.24 and homogenous perception as it is shown by the standard deviation of 0.759 . Table 4.3 results also indicated that BPR has guidance, procedures and controls as risk controlling tool of 4.14 (high mean) and then 0.718 of homogeneity standard deviation. Many respondents were in agreement that guidelines on the price risk in the bank's investment portfolio are clearly defined and communicated of 3.67 high mean and heterogeneity standard deviation of 1.004. There are sufficient rules on investment risks in relation to foreign exchange and trade 3.76 as high mean and .532 of homogeneity standard deviation. There are sufficient and effective guidelines involving interest risk of 3.76 high means, homogeneity standard deviation 0.759 . In addition, many respondents agreed on the item that the bank adheres to guidelines on investment concentration by diversify its investments of 3.62 high mean and homogeneity and 0.795 standard deviation. About item that all investment activities and decisions are deliberated and cross checked before approval of a high mean 3.62 and 0.909 homogeneity standard deviation. Finally, the table 4.3 indicated that many respondents agreed on item that investment strategies are well defined in BPR to ensure progress on a high mean of 3.62 and homogeneity responses as the standard deviation of 0.909 is less than one $(\mathrm{SD}<1)$

Table 4. 4 Overall risk management tools of BPR

\begin{tabular}{llllll}
\hline Risk management tools & $\mathrm{N}$ & Minimum & Maximum & Mean & Std. Deviation \\
\hline Standard and reports & 42 & 3.33 & 4.75 & 4.119 & .437 \\
Position limit and rules & 42 & 3.44 & 4.89 & 4.047 & .455 \\
Investment guideline and strategies & 42 & 2.75 & 4.62 & 3.803 & .585 \\
\hline
\end{tabular}

Source: Primary Data, 2021

The Table 4.4 show that many respondents were in agreement that standard and reports analysis has impact on financial performance of BPR as it is indicated by a high mean of 4.119 and homogeneity in responses as a standard deviation of 0.437 is less than one $(\mathrm{SD}<1)$. From these findings, it is clear that standard and reports analysis have a great influence on BPR financial performance. This feedback of highest level from respondent is an evidence that standards and reports contributes a lot to the financial performance and this can be spark to the smooth running of business hence empowering financial performance. The table 4.4 indicates that many 
respondents were in agreement that position limit and rules are very important in BPR as it is indicated by 4.047 (high mean) and homogeneous in responses where the standard deviation of 0.455 is less than one (SD<1), this has an implication that position limit and rules contribute to BPR in its financial performance.

The Table 4.4 finally indicated that many respondents are agreeable that investment guideline and strategies impact positively the financial performance as it is specified with high mean of 3.803 and homogeneous standard deviation of 0.585 is less than one ( $\mathrm{SD}<1)$. Results concur with that of Naceur and Omran (2008), on how tools, regulations and concentration on appropriate measures within financial institution sector helps to determine institutions' profits especially in Middle and East North Africa (MENA) countries and they should be in line with organization institution target to improve and achieve its financial performance, consistent monitoring and checking is required to prevail risk that might arise.

\subsection{To analyze the financial performance of BPR in Rwanda.}

Table 4. 5 BPR Financial performance from $2015-2018$

\begin{tabular}{llllll}
\hline Year & 2015 & 2016 & 2017 & 2018 & Trend \\
\hline Return on equity (ROE) & $5.32 \%$ & $1.7 \%$ & $2.5 \%$ & $9.4 \%$ & $4.73 \%$ \\
Return on Asset (ROA) & $0.51 \%$ & $0.3 \%$ & $0.4 \%$ & $1.4 \%$ & $0.65 \%$ \\
Net interest margin (NIM) & $13.1 \%$ & $13.4 \%$ & $12.8 \%$ & $11 \%$ & $0.12 \%$ \\
\hline
\end{tabular}

Source: BPR Annual Report 2018

Table 4.5 shows that return on equity trend is $4.73 \%$ which reveals that BPR has got positive outcome and this is due to high profit obtained. In 2015, BPR had high profit compared to 2016 and 2017 because there was low competition since market (population) trusted local bank (BPR) which started its business journey in 1975 in Nkamba village in eastern province and this created better opportunity. In 2016 and 2017 there is decrease in as far ROE is concerned and this was due to new BPR strategies to build up strong bank based on today's market needs and led to high costs leading to low profit. In addition, there was emerging stiff competition and wellestablished foreign banks including equity bank, Kenya commercial bank (KCB) and other banks joined market before. In 2018, BPR had increase increased return on equity due to constant increase of profit as result of technology innovation implementation such as mobile banking service, internet banking, strengthening and updating payment service (RIPPS), issuing debit card and reviewing service channels for instance Loan facilities. Revamping systems and empowering service led to profit maximization as result of charges and commissions collected by the bank. These challenges and opportunities mentioned above also affected negatively return on asset (ROA) in respective years but in 2018 increased up to $1.4 \%$ from $0.5 \%$ (2015) and this was due standardizing technology in bank services.

Further still, it is clearly shown net interest margin (NIM), relies between $11 \%$ and $13.1 \%$ in four years. The trend is relatively $0.12 \%$ because the bank always set annual plan and budget to align interest received against payment interest. According to Yeboah (2016), NIM determined by internal characteristics, bank industry in Rwanda and Regulator (BNR). Central bank plays big a role in determining interest rate applied by the bank and monitoring interest implemented by the bank to avoid over charging customer.

Capital adequacy reveals measure of bank's capital against to risk and it used to promote the stability and efficiency of financial systems in the bank. According to regulator capital adequacy ratio should be above $15 \%$ but BPR findings shows that 2015 has $12.76 \%$ and this was due high risk since there was no strong measures in place while from 2016 to 2018 ratio is between $23.1 \%$ and $23.9 \%$ due to advanced control as the Bank operations continue to grow and compete on market. Results didn't contradict with study carried out by Froot, Scharfstein and Stein (2003) where sources of finance are more cost and affect funds to be generated and basing in table 4.5 , it shows that BPR had less net interest margin in 2018 compared to 2015 and 2016 due to high investment costs to improve its business operations and staff competition encountered as result of rising up of other banks in Rwanda.

\subsection{Establishment of Relationship between risk management tools and financial performance of BPR in} Rwanda

\begin{tabular}{lllll}
\hline \multicolumn{2}{l}{ Model Summary } & & & \\
\hline Model & $\mathrm{R}$ & R Square & Adjusted R Square & Std. Error of the Estimate \\
& $.723^{\mathrm{a}}$ & .523 & .509 & .467 \\
\hline
\end{tabular}

a. Predictors: (Constant), Position limit and rules, standard and reports, investment guideline and strategies Source: Primary Data, 2021

Adjusted R squared explains the variation in the dependent variable as result of changes in independent variable, the results in Table 4.6 indicated the value of adjusted $R$ squared 0.509 indicates the variation of $50.9 \%$ reflect to BPR performance, this was because of changes in position limit and rules, standard and reports, investment guideline and strategies at $95 \%$ confidence interval. Therefore $50.9 \%$ changes in performance to BPR's business could be resulted and caused by position limit and rules, standard and reports, investment guideline and strategies. 
This indicated that the other variables (factors) that were not studied in this study contributed $49.1 \%$ of the variability on BPR financial performance. $\mathrm{R}$ is the correlation coefficient that indicates relationship between the studies variables; the findings prove that there was a strong positive relationship (0.723) between the study variables.

Table 4.7 Analysis of variance (ANOVA)

\begin{tabular}{llllll}
\hline Model & Sum of Squares & Df & Mean Square & F & Sig. \\
\hline Regression & 25.386 & 2 & 8.462 & 38.714 & $.000^{\mathrm{a}}$ \\
Residual & 23.169 & 40 & .219 & & \\
Total & 48.555 & 42 & & & \\
\hline
\end{tabular}

a. Predictors: (Constant), Position limit and rules, standard and reports, investment guideline and strategies

b. Dependent Variable: Financial performance

Source: Primary Data, 2021

The ANOVA report which assessed the overall significance of the regression model applied in this study indicated that, $\mathrm{p}<0.5$ (Sig. $=0.000$ ) and therefore the model was significant at $95 \%$ confidence level. This shows that position limit and rules, standard and reports, investment guideline and strategies influence positively financial performance of BPR.

\section{Table 4. 8 Regression Coefficients}

\begin{tabular}{|c|c|c|c|c|c|}
\hline \multirow[b]{2}{*}{ Model } & \multicolumn{2}{|c|}{ Unstandardized Coefficients } & Standardized Coefficients & \multirow[b]{2}{*}{$\mathrm{T}$} & \multirow[b]{2}{*}{ Sig. } \\
\hline & B & Std. Error & Beta & & \\
\hline (Constant) & .344 & .186 & & 1.851 & .047 \\
\hline Position limit and rules & .454 & .147 & .883 & 3.088 & .003 \\
\hline standard and reports & .291 & .239 & .147 & 2.381 & .034 \\
\hline $\begin{array}{l}\text { investment guideline } \\
\text { strategies }\end{array}$ & and .314 & .305 & .025 & 1.046 & .023 \\
\hline
\end{tabular}

Dependent Variable: Financial performance

Source: Primary Data, 2021

The linear regression model for this study was $\mathrm{Y}=\mathrm{pO}+\mathrm{p} 1 \mathrm{X} 1+\mathrm{p} 2 \mathrm{X} 3+\mathrm{p} 3 \mathrm{X} 3+\epsilon$, Where: $\mathrm{Y}=$ Financial Performance, $\mathrm{X} 1$ = Position limit and rules, $\mathrm{X} 2=$ Standard and reports, $\mathrm{X} 3$ = Investment guideline and strategies, pO $=$ the constant, $\epsilon=$ error term. As per the SPSS results generated, the equation translates to: Financial performance $=0.344+0.454 \mathrm{X} 1+0.291 \mathrm{X} 2+0.314 \mathrm{X} 3$. Where; financial performance $=$ Constant + Position limit and rules + Standard and reports + Investment guideline and strategies.

The findings in Table 4.8 imply that position limit and rules relates positively with financial performance, the relationship is statistically significant since $(\beta=0.454, \mathrm{p}<0.05 ; \mathrm{p}=0.003)$; There is a positive relationship between position limit and rules and financial performance of BPR. Standard and reports which is statistically significant since $(\beta=0.291, \mathrm{p}<0.5 ; \mathrm{p}=0.034)$; and investment guideline and strategies relates positively with financial performance of BPR and the relationship is significant since $(\beta=0.314, \mathrm{p}<0.5 ; \mathrm{p}=0.023)$. Results indicates that there is relation

Therefore, Results indicated in Table 4.6 shows that $r=0.723$ the relationship between dependent variable and independent variable is positively significant. In this context, the figures indicate that any change in dependent variables leads to change in financial performance of BPR. Research findings did not contradict previous observation from empirical studies carried out by Afolabi (2020), who revealed that return on equity, return on asset and net interest margin are core determinants of level of institution profitability.

\subsection{Conclusion}

In conclusion, the study dealt with the exploration of risk management tools and financial performance of commercial banks in Rwanda; it was extended basing on the following specific objectives: to ascertain risks management tools used by BPR in managing its assets, to analyze the financial performance of BPR in Rwanda and to find the link concerning risk management tools and financial performance of commercial bank in Rwanda. Therefore, the results of the study indicated that risk management tools used by BPR to manage asset contribution have great positive impact to the financial performance. This confirms that if asset well managed by the bank and utilized effectively, this will minimize risk but also improve financial statement hence the management has to ensure all assets are recorded and monitored regularly. Secondly regarding analyzing financial performance of BPR, there is good trend of profit which comes from mitigation of risk within the bank. This requires consistent and regular profit evaluation of income against expense. 
In addition to this, the result shows that there is link and dependency between two variables, risk management tools has impact to financial performance of banks. This implies that once risk management tools are effectively implemented, they will definitely lead to high financial performance of commercial banks and vice versa. BPR financially has improved well due to risk management tools utilized since 2015 to 2018. Lastly, basing on the study findings, the researcher concluded that risk management tools greatly influence BPR financial performance as justified P-values which are positive and statistically significant hence, for this reason, the results have therefore shown that the objectives of this research have been met. Furthermore, the findings indicate the link where financial performance can't be achieved without proper implementation of risk management tools.

\subsection{Acknowledgement}

Firstly, special thanks to Almighty God enabled me to accomplish the task that was not easy but he gave me strength and means to pursue up to the end. Without his empowerment, I would not have finished this journey. He deserves praise. The greatest thanks go to my both parents (Karekezi Emmanuel and Mukarutabana Colletta) and my lovely wife Murekatete Angelique for their love and support provided to me during my journey. I can never forget the assistance of my entire family members who assisted directly or indirectly. Required assistance and comfort was available to facilitate to reach the target. I also appreciate respondents and BPR who agreed to take their time and go through questionnaire but also provided genuine response that supported my research to go smoothly. Lastly but not least, I thank my classmate, entire staff and management of Mount Kenya University who provided conducive environment in order to improve my carrier and inherit standard knowledge.

\section{References}

[1].Afolabi, T. S. (2020). Credit Risk and Financial Performance: Evidence from Microfinance Banks in Nigeria. Banque Populaire du Rwanda (BPR). Annual report 2015 -2018. Rwanda: Kigali

[2].Belassi, W., \& Tukel, O. I. (1996). A new framework for determining critical success/failure factors in projects. International journal of project management, 14(3), 141-151.

[3].Chen, K., \& Pan, C. (2012). An empirical study of credit risk efficiency of banking industry in Taiwan. Web

[4].Journal of Chinese Management Review, 15(1), 1-16.

[5].Drehmann, M., \& Goodhart, C. (2000). Is Cash Becoming Technologically Outmoded? Or Does it Remain Necessary to Facilitate" Bad Behaviour"? An Empirical Investigation into the Determinants of Cash Holdings. LSE Financial Markets Group.

[6].Epure, M., \& Lafuente, E. (2015). Monitoring bank performance in the presence of risk. Journal of Productivity Analysis, 44(3), 265-281.

[7].Kane, E. J. (2008). Regulation and supervision: an ethical perspective (National Bureau of Economic Research No. w13895). Massachusetts: National Bureau of Economic Research. https://www.nber.org/system/ files/working_papers/ w 13895/w13895.pdf

[8].Kaplan, R. S., Kaplan, R. E., Norton, D. P., Davenport, T. H., \& Norton, D. P. (2004). Strategy maps: Converting intangible assets into tangible outcomes. Harvard Business Press.

[9].Ministry of Finance and Economic Planning. Budget report 2010/2011, MINECOFIN, Rwanda: Kigali

[10]. Naceur, S. B., \& Omran, M. (2008, January). The effects of bank regulations, competition and financial reforms on MENA banks' profitability. (Economic Research Forum No. 449). Washington DC: Economic Research Forum.

[11]. Ndegwa, R. (2014). Effect of mobile money on non-performing loans of commercial banks in Kenya: Doctoral dissertation, University of Nairobi.

[12]. Vandello, J. A., \& Bosson, J. K. (2013). Hard won and easily lost: A review and synthesis of theory and research on precarious manhood. Psychology of Men \& Masculinity, 14(2), 101.

[13]. Van Greuning, H., \& Bratanovic, S.B (2009). Analyzing Banking Risk, A Framework for Assessing Corporate Governance and Financial Risk. The World Bank.

[14]. Van Oorschot, L. (2010). Risk reporting: An analysis of the German banking industry

[15]. Yeboah, E. A. (2016). Determinants of bank net interest margin: does monetary union membership matter?

[16]. Doctoral dissertation, Brunel University London. 